\title{
The stability of precipitates under electropulsing in 316L stainless steel
}

\author{
W.J. Lu, X.F. Zhang and R.S. Qin* \\ Department of Materials, Imperial College London, Exhibition Road, London SW7 2AZ, \\ United Kingdom
}

\begin{abstract}
Precipitation takes place when the austenite stainless steel is heated to a high temperature. This is found significantly different when the electropulsing is implemented during the heat treatment. Considerable less number density and much smaller particle size of precipitates are formed in the sample treated with electropulsing. Electropulsing helps to dissolve precipitates. The effect is not due to Ohm heat. Instead, it is attributed to the electric-current-induced change of thermodynamic sequences of the phases and the electric-current-accelerated mass diffusion.
\end{abstract}

Keywords: Electropulsing; precipitation; $\chi$-phase; free energy

*Corresponding author. Tel.: +44 (0)20 7594 6803; Fax: +44 (0)20 7594 6757; Email:

r.qin@imperial.ac.uk (R.S. Qin) 


\section{Introduction}

Precipitates are typically small particles, consist of high solute composition, and are formed in supersaturated alloys. ${ }^{1}$ Coarsening of precipitates can give rise to the loss of strength, localization of stress, initiation of crack, creeping and many other detrimental effects. ${ }^{2,3}$ This takes place frequently in engineering alloys implemented at an elevated temperature especially after long durations. ${ }^{4}$ Examples include the stainless steel implemented in nuclear engineering as reactor vessels, boilers and piping systems, ${ }^{5}$ and creep-resistant steel used as turbine blades in power plant. ${ }^{3,4}$

Normally, the precipitates have different electrical conductivities from the steel matrix. The different configurations of the precipitates in steel affect the electrical current distribution in the whole system. The different current distributions correspond to various system free energies. ${ }^{6,7}$ It is suggested that electric current may affect the formation of object with different electrical conductivity from that of matrix. This may provide a possibility to use electric current to affect the formation of precipitates. Pulsed electric current, as an instantaneously high energy input method, can affect the precipitation process, grain boundary migration and phase transformations in some alloys. ${ }^{7-10}$ Experimental results show that the dissolution rate of $\beta-\mathrm{Mg}_{17} \mathrm{Al}_{12}$ phase in aged $\mathrm{Mg}-9 \mathrm{Al}-1 \mathrm{Zn}$ alloy can be enhanced ${ }^{9}$ and the migrate rate of grain boundaries in $\alpha$-Ti alloy can be accelerated ${ }^{10}$ even the nucleation of cementite in pearlite is promoted by electric current. ${ }^{7}$

The primary aim of this work was to explore the possibility of using electrical current to dissolve precipitates in 316L stainless steel instantly using its non-thermal effect so that the stainless steels implemented in the earlier mentioned environments can have their microstructure and properties recovered in-situ rather than be replaced. 


\section{Experimental}

Fe-10.45Ni-16.68Cr-2.02Mo (at.\%) is a typical 316L stainless steel. Its phase diagram is calculated using Thermo_Calc 3.1 and TCFE7 commercial database, as illustrated in Fig 1. The alloy is in fully austenite crystal structure when the temperature is between $1125.15 \mathrm{~K}$ and $1495.88 \mathrm{~K}$. Precipitation tends to take place when the temperature is lower than 1125.15 $\mathrm{K}$. In engineering manufacturing, the steel is quenched from $1273.15 \mathrm{~K}$ to ambient temperature to avoid precipitation. The mobility of $\mathrm{Ni}, \mathrm{Cr}$ and $\mathrm{Mo}$ is extremely low at ambient temperature which prevents the precipitation from taking place. However, precipitation takes place when the steel is in service at elevated temperatures. The purpose of this experiment is to prove if electric current can be used to dissolve precipitates at the elevated temperatures.

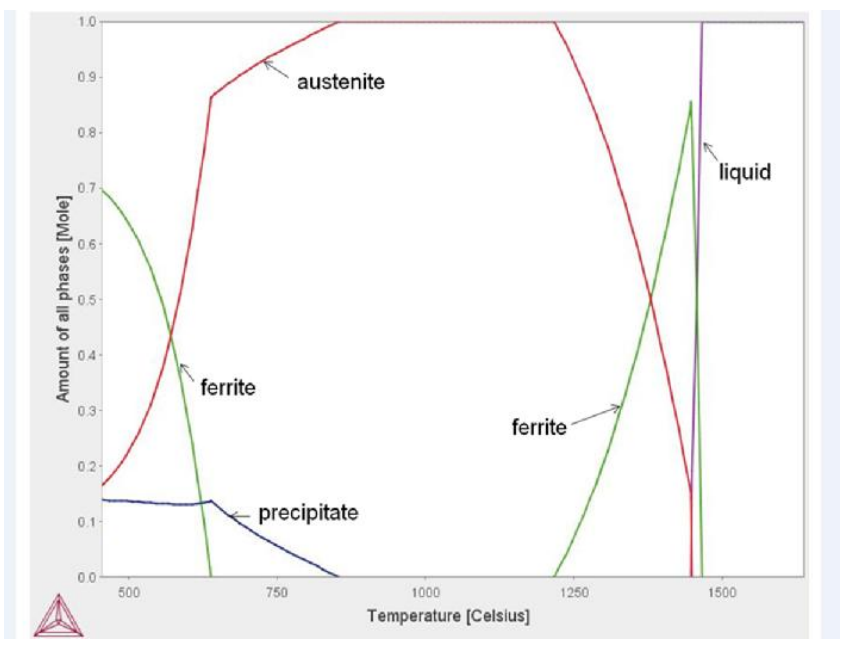

Fig. 1 The equilibrium phase diagram of Fe-10.45Ni-16.68Cr-2.02Mo (at.\%) alloys

A fully austenitic hot rolled steel plate was received, cold rolled from $3.0 \mathrm{~mm}$ to $0.5 \mathrm{~mm}$ in thickness, and cut into oblong-shaped specimens with their longest edge perpendicular to the rolling direction. A pair of samples were heated by radiative heating in an electric furnace at 1023.15 $\mathrm{K}$ for 60 mins and then quenched into cold water. During annealing, one of the 
samples was connected to an electropulse generator using copper wire. The pulse generator provides pulsed electric current to the sample. Each pulse lasts $60 \mu$ s and the current density is $6.3 \times 10^{7} \mathrm{~A} / \mathrm{m}^{2}$. There is only one pulse in each second. The electric power consumption in this treatment is $0.0028 \mathrm{~W}$. Both samples in the furnace were exposed to the same annealing conditions. The Joule heat is negligible. After the treatment, both samples were quenched into cold water simultaneously. The quenched samples were moulded, mechanically ground, polished and etched with a solution made by $20 \mathrm{ml}$ hydrochloric acid, $10 \mathrm{ml}$ nitric acid and $20 \mathrm{ml}$ glycerine. The microstructure characterizations were carried out using scanning electron microscopes (SEM) and focused ion beam secondary ion mass spectrometry (FIBSIMS). For the TEM observation, specimens were mechanically polished to a thickness of approximately $30 \mu \mathrm{m}$, punched to the disc specimens with $3 \mathrm{~mm}$ in diameter by a brass cutter. The disc specimens were electrically polished using a mixture solution $(30 \mathrm{ml}$ perchloric acid and $270 \mathrm{ml}$ acetic acid) at $15{ }^{\circ} \mathrm{C}$ and observed by TEM operated at an acceleration voltage of $200 \mathrm{kV}$. The electrical conductivity of specimens with and without pulsed electric current was measured by Microhmmeter (DO5000 series).

\section{Results and discussion}

Fig. 2(a) shows a bright-field image of the steel without pulsed electric current. A high frequency of precipitates was observed both along the grain boundaries and within the grains. These precipitates appear as dark particle in the image. One of the particles is selected randomly for the diffraction examination. According to the lattice parameters and crystal structure demonstrated in Fig. 2(b) and 2(c), the precipitate particle is $\chi$-phase and the matrix is austenite. It is possible that other precipitates are with other structures. $\chi$-phase is an intermetallic compound belonging to the tetrahedrally close-packed phases. It has a chemical composition of $\mathrm{Fe}_{36} \mathrm{Cr}_{12} \mathrm{Mo}_{10}$ and with a complex cubic structure that is frequently found in 
austenitic stainless steels underwent a long time treatment at the moderate temperature. ${ }^{11-13}$ The characterization from the electropulsed steel also confirmed the present of $\chi$-phase in the annealing.

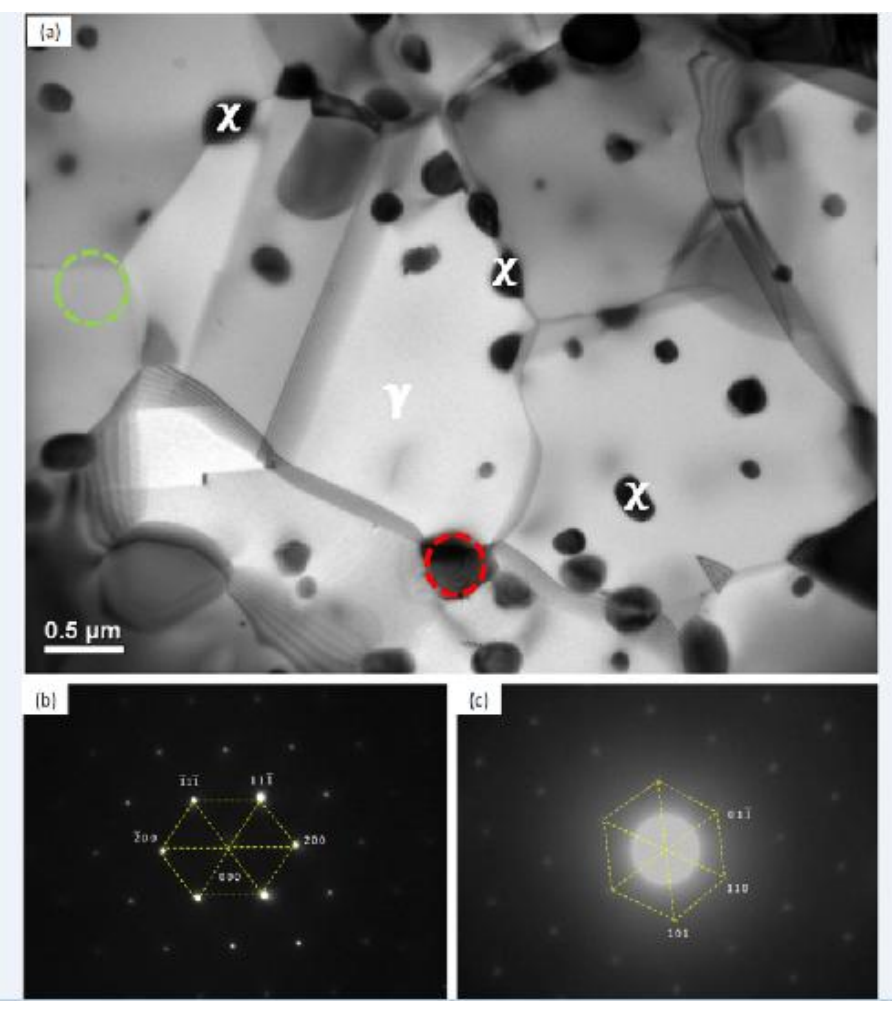

Fig. 2 (a) Bright field image by TEM; (b) Selected area diffraction pattern of austenitic matrix; (c) Diffraction pattern of $\chi$-phase precipitation, where the selected area diffractions for austenite and $\chi$-phase precipitation are marked by circles.

Fig 3 (a), (c) and (e) illustrate the distribution of precipitates in the sample without electropulsing treatment. The particles are distributed randomly. Some of them are indicated by the arrows. The precipitates distribution in the sample with electropulsing treatment is presented in Fig. 3(b), 3(d) and (f). The average size of the precipitates in electropulsed sample is much smaller than that of without electropulsing treatment. In order to better characterize the size and number distribution with and without electropulsing treatments, 

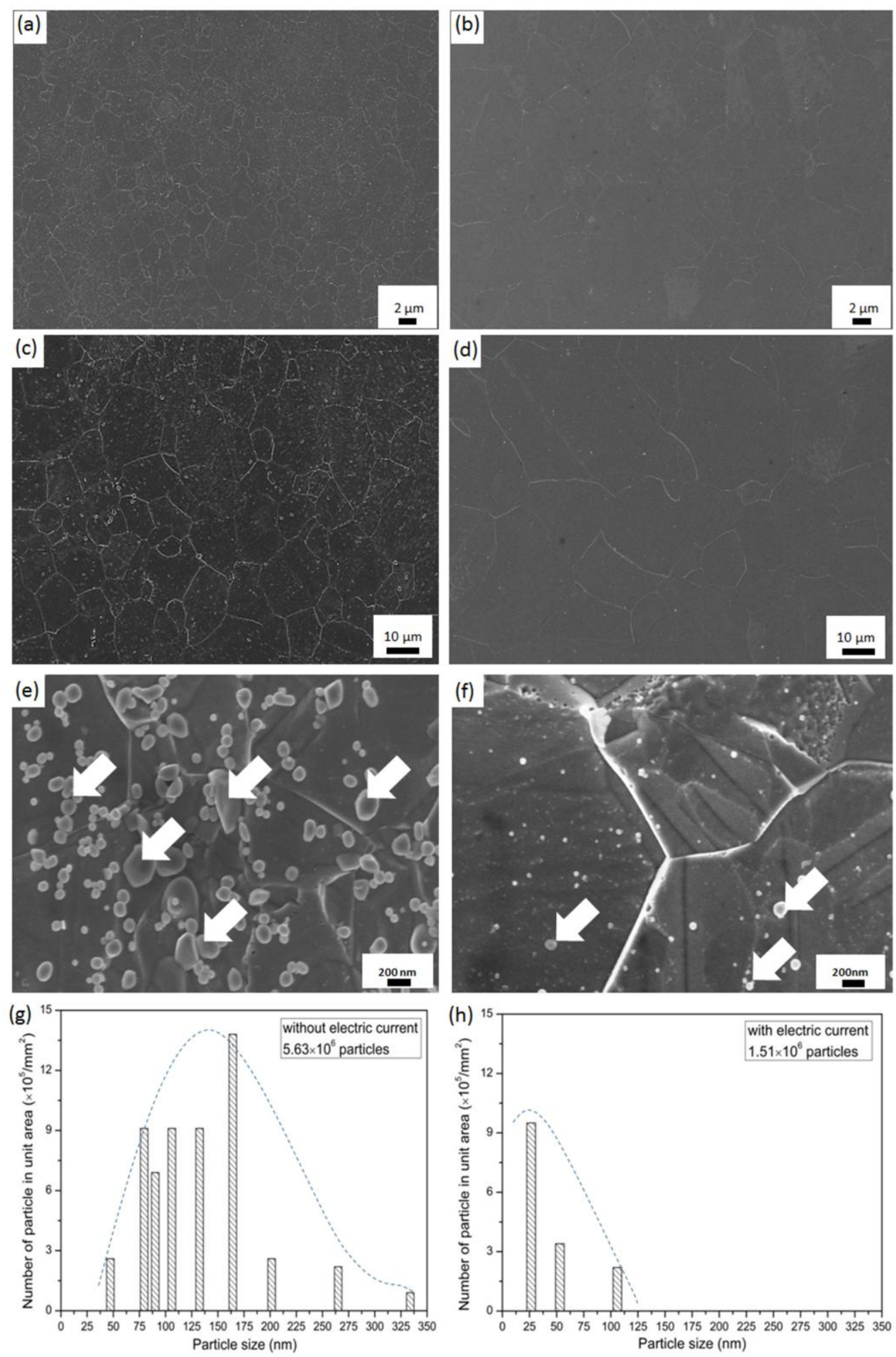

Fig. 3 (a), (c) and (e) show the distribution of precipitates in the sample without pulsed electric current treatment. (b), (d) and (f) show the distribution of precipitates with pulsed electric current treatment. (g) and (f) show the number distributions of precipitates without and with pulsed electric current treatments, respectively. 
further statistical analysis by means of histograms and peaks fitting using Lorentzian has been carried out. Individual precipitate particles with equivalent circular diameter are measured. The results are presented in Fig 3(g) and 3(h), respectively. The particle in the steel without electropulsing has a wide variation in size $(43 \mathrm{~nm} \leq$ particle diameter $\leq 330 \mathrm{~nm})$, but its size distribution mainly concentrates in approximately $143 \mathrm{~nm}$ according to Lorentzian fitting, see Fig. 3(g). In the case of electropulsed steel, the particles are dispersed with the varied size of 25-105 nm, and its distribution mainly concentrates in $25 \mathrm{~nm}$ (Fig 3 (h)). Furthermore, the number density of particles in the electropulsed steel $\left(\sim 1.51 \times 10^{6}\right.$ per unit area) is 3.7 times smaller than that of the steel without electropulsing treatment $\left(\sim 5.63 \times 10^{6}\right.$ per unit area). Therefore, not only the size but also the number density of particles is dramatically reduced by electropulsing. It indicates that the precipitates are dissolved by electropulsing significantly.
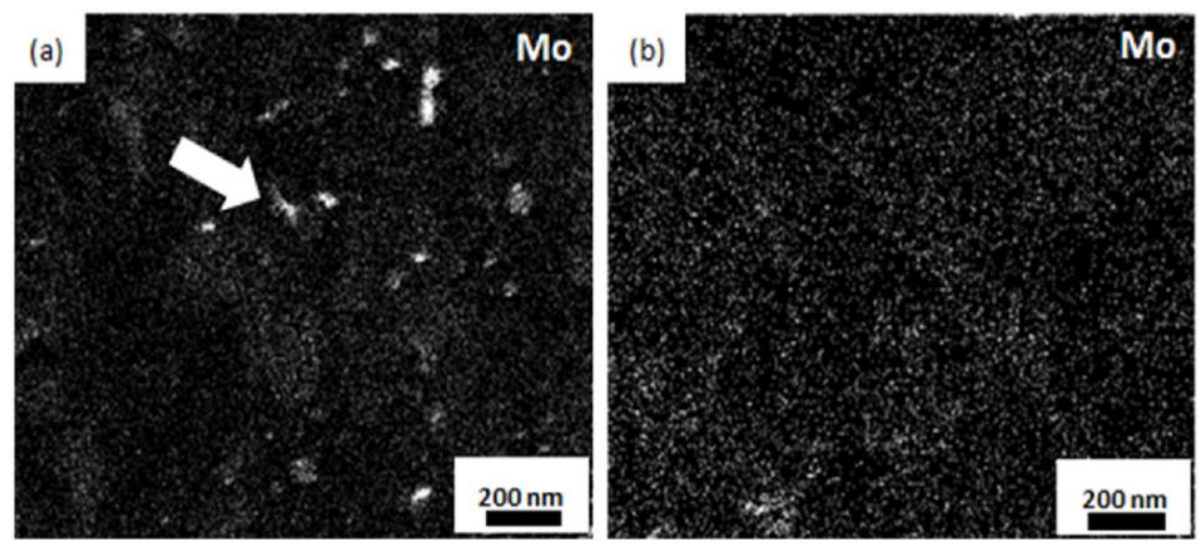

Fig. 4 FIB-SIMS images for molybdenum mapping in the samples (a) without and (b) with pulsed electric current treatment, respectively.

Molybdenum atoms occupy the largest atomic sites in the $\chi$-phase structure. ${ }^{11}$ The detection of Mo distribution will help to understand the effect of electropulsing on the solute segregation. FIB-SIMS is an analytical technique that can provide parts per million (ppm) to parts per billion (ppb) sensitivity for most solutes when relatively large areas of analysis are 
available. Therefore, it can provide good depth resolution for the molybdenum distribution, which is better than using energy dispersive spectrometry. Fig 4 exhibits the micrograph and chemical mapping of molybdenum in the samples without and with electropulsing treatments, respectively. For the steel without electropulsing treatment, as demonstrated in Fig. 4(a), precipitates are randomly dispersed in the matrix and molybdenum elements are mainly concentrated on these particles. Most precipitates are disappeared by electropulsing treatment and molybdenum distribution is almost homogenously in the matrix, as shown in Fig 4(b). The mapping analysis by SIMS suggests that pulsed electric current diminished solute segregation. This also indicates the dissolution of precipitates.

Since the thermal effect affects the microstructural evolution, ${ }^{7-10}$ the temperature raised by each electric current pulse has been calculated. Each pulse causes $6.5 \times 10^{-3} \mathrm{~K}$ temperature rising when the pulse duration is $60 \mu \mathrm{s}$. The pulse in the present experiment is with $1 \mathrm{~Hz}$ frequency. It means that the maximum temperature rising rate due to applying electric current is $6.5 \times 10^{-3} \mathrm{~K} / \mathrm{s}$. The Joule heating is hence negligible in the present work. The observed effect of electric current on the precipitation evollution must be due to athermal effect. Usually, electric current promotes the solute diffusion, dislocation migration and interface kinetics. ${ }^{7-10}$ The drift electrons driven by the applied electrical potential are scattered unevenly around defects. ${ }^{14}$ The uneven distribution of electrons around the defects causes anisotropic shielding effect to the electromagnetic forces between an atom and its neighbours. This brings the kinetic barrier down. The mobility of a substitutional atom is expressed generally as

$$
M=M_{a} \exp \left(-\frac{\Delta E_{k}}{K T}\right)
$$

where $M_{a}$ is the pre-exponential factor dependent on the frequency of atom hopping and lattice distance, $\Delta E_{k}$ is the kinetic barrier, $K$ is the Boltzmann constant, $T$ is the temperature 
and $M$ is the mobility. The reduction of $\Delta E_{k}$ will cause the increment of mobility. The acceleration effect of pulsed electric current contributes to the faster microstructure evolution of a material. This enhanced mobility may help precipitates to evolve to either direction of coarsening or dissolving more quickly. Thermodynamics will tell whether the precipitates are driven to grow or to shrink by electropulsing.

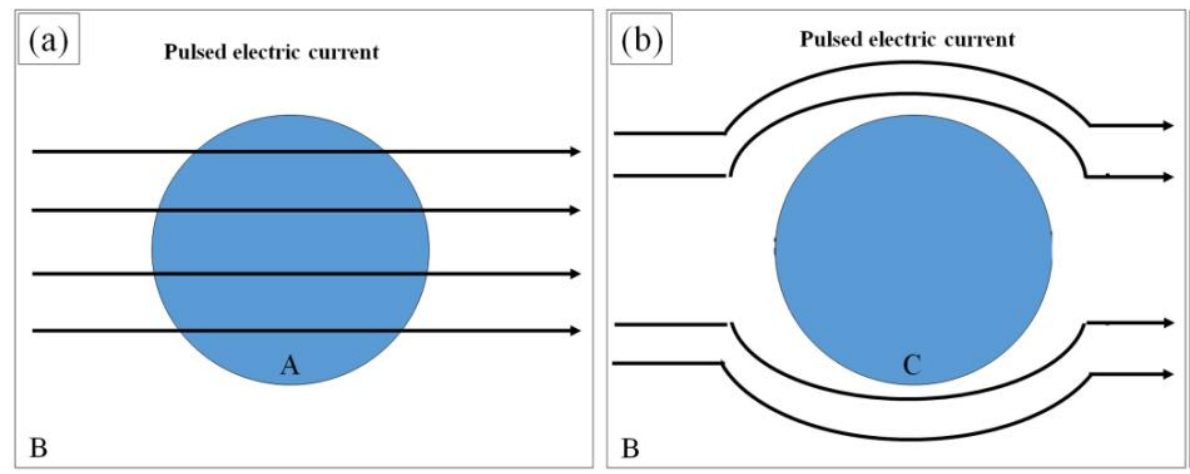

Fig. 5 Schematic diagram for the electric current streamlines in a matrix containing a spherical precipitate with (a) the same electrical conductivities as that of the matrix and (b) the smaller electrical conductivities than that of the matrix.

In order to understand the effects of pulsed electric current on the precipitation in $316 \mathrm{~L}$ stainless steel, a schematic diagram is plotted in Fig 5. The electric current streamline distribution will be different if the conductivity of precipitate is different from that of matrix. This alternation of the electric current distribution leads to change of system free energy. Thus the system free energy in Fig 5(a) can be significantly different from that in Fig 5 (b). The system free energy of a steel specimen consists of three terms, namely the chemical free energy of the bulk phases $\left(\Delta G_{c h e m}\right)$, interface free energy $\left(\Delta G_{\text {surf }}\right)$ and the free energy associated to the passing electric current $\left(\Delta G_{\text {elec }}\right)$. The system free energy change in microstructural evolutions $(\Delta G)$ is represented as

$$
\Delta G=\Delta G_{\text {chem }}+\Delta G_{\text {surf }}+\Delta G_{\text {elec }} .
$$


The microstructure evolutions is determined by the irreversible law of thermodynamics

$$
\Delta G \leq 0
$$

For the specimen without electric current, $\Delta G_{\text {elec }}=0$. Microstructural evolutions happens when $\Delta G_{\text {chem }}+\Delta G_{\text {surf }} \leq 0$. For the specimen with electric current treatment, the precipitates will dissolve when $\Delta G_{\text {elec }}>0$. The latter is obtainable from the expression of

$$
\Delta G_{\text {elec }}=\frac{\mu}{8 \pi} \iint \frac{\vec{j}_{b}(r) \vec{j}_{b}\left(r^{\prime}\right)-\vec{j}_{a}(r) \vec{j}_{a}\left(r^{\prime}\right)}{\left|r-r^{\prime}\right|} d r d r^{\prime}
$$

where $\mu$ is the magnetic permeability. $\vec{j}_{b}(r)$ and $\vec{j}_{a}(r)$ are current density distributions before and after the applying electric current, respectively. $r$ and $r^{\prime}$ are two different positions inside the specimen. The calculation of $\Delta G_{\text {elec }}$ requires the distribution of current density. The latter requires the electrical conductivity of all phases before and after the microstructure evolution. Previously it has been observed the segregation of $\mathrm{Pb}$ to grain boundaries in $\mathrm{Cu}-\mathrm{Zn}$ alloys under pulsed electric current due to the change of Gibbs free energy associated to the discrepancy of electrical conductivities. ${ }^{15}$ In present work, the microstructure evolution toward increasing the system electrical conductivity is promoted by electropulsing. Our measurement shows that the bulk electric conductivity of un-electropulsed specimen is $1.82 \times 10^{6} \mathrm{~s} / \mathrm{m}$, while that of the pulsed specimen is $2.21 \times 10^{6} \mathrm{~s} / \mathrm{m}$. The electrical conductivity of specimen is increased by $21.4 \%$ after electric current treatment. This is in agreement with the theoretical and experimental prediction. In the case of $\chi$-phase precipitation, Eq. (4) can be calculated when the relationships between the chemical compositions of all phases in the steel and their electrical conductivity are established. This experiment proves that electric current has not only retarded the growth of precipitates but also dissolved the formed precipitates. The results cannot be explained merely by PEC retarding precipitation growth. Each pulse lasts $60 \mu$ s whereas the pulse frequency is $1 \mathrm{~Hz}$, so only a minor fraction of the 
total time experiences PEC and correspondingly little net effect would be expected. Therefore, we conclude that electropulsing dissolves the precipitates.

\section{Conclusion}

In summary, this work has shown that the precipitates in $316 \mathrm{~L}$ stainless steels can be dissolved by the electropulsing. Different size and number density of precipitates cause different electric current distributions. The corresponding system free energy is changed by the passing electric current. The electropulsing-accelerated kinetics allows to dissolve precipitate that formed in a relative long duration between pulses.

\section{Acknowledgment}

This work was financially supported by the Royal Academy of Engineering, EPSRC (No. EP/J011460/1) and TATA Steel at United Kingdom. 


\section{References}

1. D. H. Bratland, Ø. Grong, H. Shercliff, O. R. Myhr and S. Tjøtta: 'Modelling of precipitation reactions in industrial processing', Acta Mater., 1997, 45, 1-22.

2. C. Donadille, R. Valle, P. Dervin and R. Penelle: 'Development of texture and microstructure during cold-rolling and annealing of fcc alloys - example of an austenitic stainless-steel', Acta Mater., 1989, 37, 1547-1571.

3. H.K.D.H. Bhadeshia: 'Design of ferritic creep-resistant steels', ISIJ Inter., 2001, 41, 626640.

4. R.C. Thomson and H.K.D.H. Bhadeshia: 'Changes in chemical-composition of carbides in 2.25Cr-1Mo power-plant steel .1. Bainitis microstructure' Mater. Sci. Tech., 1994, 10, 193-204.

5. G.S. Was, P. Ampornrat, G. Gupta, S. Teysseyre, E.A. West T.R. Allen, K. Sridharan, L. Tan, Y. chen, X. Ren and C. Pister: 'Corrosion and stress corrosion cracking in supercritical water', J. Nucl. Mater., 2007, 371, 176-201.

6. X.F. Zhang and R. S. Qin: 'Electric current-driven migration of electrically neutral particles in liquids', Appl. Phys. Lett., 2014, 104, 114106.

7. R.S. Qin, E.I. Samuel and A. Bhowmik: 'Electropulse-induced cementite nanoparticle formation in deformed pearlitic steels', J. Mater. Sci., 2011, 46, 2838-2842.

8. H. Conrad: 'Effects of electric current on solid state phase transformations in metals', Mater. Sci. Eng. A., 2000, 287, 227-237.

9. Y. B. Jiang, G. Y. Tang, C. H. Shek, Y.H. Zhu, Z.H. Xu: 'On the thermodynamics and kinetics of electropulsing induced dissolution of $\beta-\mathrm{Mg}_{17} \mathrm{Al}_{12}$ phase in an aged $\mathrm{Mg}-9 \mathrm{Al}-$ 1Zn alloy, Acta Mater., 2009, 57, 4797-4808.

10. Z. S. Xu, Z. H. Lai and Y. X. Chen: 'Effect of electric-current on the recrystallization behavior of cold-worked alpha-Ti', Scripta Metall., 1988, 22, 187-190. 
11. A. Redjaïmia, A. Proult, P. Donnadieu and J.P. Morniroli: 'Morphology, crystallography and defects of the intermetallic $\chi$-phase precipitated in a duplex $(\delta+\gamma)$ stainless steel', $J$. Mater. Sci., 2004, 39, 2371-2386.

12. Y. Song, T.N. Baker and N.A. McPherson: 'A study of precipitation in as-welded 316LN plate using 316L/317L weld metal', Mater. Sci. Eng. A., 1996, 212, 228-234.

13. M.J. Cieslak, A.M. Ritter and W.F. Savage: ' $\chi$-phase formation during solidification and cooling of Cf-8m weld metal', Weld. Res. Suppl., 1984, 63, S133-S140.

14. P.S. Ho and T. Kwo: '" 'Electromigration in metals', Rep. Prog. Phys., 1989, 52, 301-348.

15. X.L. Wang, J.D. Guo, Y.M. Wang, X.Y. Wu, B.Q. Wang: 'Segregation of lead in Cu-Zn alloy under electric current pulses', Appl. Phys. Lett., 2006, 89, 061910. 